\section{Temperature Influences Flowering of Pakalana (Telosma cordata Merrill) under Long Days}

\author{
Richard A. Criley ${ }^{1}$ \\ Department of Horticulture, University of Hawaii, Honolulu, HI 96822
}

Additional index words. Chinese violet, lei flower

Abstract. The flowers of pakalana are initiated under long days (LD) at $18 \mathrm{C}$ or above. At 21 and $24 C$, inflorescence initiation occurs after 3 weeks of $L D$, and the clusters grow to $6 \mathrm{~mm}$ in another 2 weeks, but at 18C, about 12 weeks are required to achieve the 6-mm length. This length is critical, as a shorter stage often fails to develop further. From a length of $6 \mathrm{~mm}$, clusters develop to anthesis in 3 to 4 weeks at 24C, 4 to 5 weeks at 21C, and 6 to 7 weeks at 18C. This work is important to the production of pakalana flowers for Hawaii's winter lei flower trade.

Pakalana is a vine belonging to the Asclepiadaceae. There are 10 species native to southeastern Asia. Chinese immigrants introduced pakalana to Hawaii in the late 1800 s. Prized for their fragrance (Arai et al., 1993), the flowers are strung into leis and presented on special occasions. Opening greenish and aging to yellow-orange, the five-part flowers are 15 to $20 \mathrm{~mm}$ long and 12 to $15 \mathrm{~mm}$ wide at the corolla. They are borne axially in clusters of two to 20 during the spring and summer in Hawaii. During fall and winter, flower production ceases.

Pakalana plants held outdoors under continuous light during winter initiated buds and flowered readily (Criley, 1989). A critical daylength was not determined, but this seemed unnecessary for commercial production when interrupted nights $\{4 \mathrm{~h}$ of incandescent or fluorescent light at levels sufficient to prevent chrysanthemum [Dendranthema $\times$ grandiflorum (Ramat) Kitamura] flower initiation $\}$ also caused flower initiation 3 to 4 weeks after the start of long days (LD) (Criley, 1989). Flower development took longer during winter than summer, and the slightly lower winter temperatures were presumed to be the cause. The objective of this work was to define temperature conditions that would permit flowering in pakalana under artificial LD.

The plant material used in these experiments was grown from the seeds of a single seed pod produced in Summer 1987. Two dozen plants were selected and potted into plastic pots holding 20 liters of a 1 soil : 1 peat : 1 perlite (by volume) medium. Wire trellises supported the vines. Through the next 3 years, they were subjected to various lighting treatments that confirmed a vegetative and reproductive response to LD (Criley, 1989). In Fall

Received for publication 22 Dec. 1994. Accepted for publication 17 Apr. 1995. Hawaii Institute of Tropical Agriculture and Human Resources Journal Series no. 4044. The cost of publishing this paper was defrayed in part by the payment of page charges. Under postal regulations, this paper therefore must be hereby marked advertisement solely to indicate this fact.

${ }^{1}$ Professor.
1990, 12 plants were trimmed to the main stems, and new growth was allowed to develop under decreasing natural daylengths (12 to $11.3 \mathrm{~h}$ ). No flower buds were evident when four plants were placed 26 Dec. 1990 in each of three growth chambers set for a constant 18 , constant 18,21 , or $24 \mathrm{C}$ under a $16-\mathrm{h}$ photoperiod.
21 , or $24 \mathrm{C}$ and a daylength of $16 \mathrm{~h}$. The light intensity at the foliar canopy was 214 $\mu \mathrm{mol} \cdot \mathrm{m}^{-2} \cdot \mathrm{s}^{-1}$, measured $60 \mathrm{~cm}$ below the light bank (twenty 40-W cool-white fluorescent tubes). Flowers, however, developed along the stem in bright light and in shaded positions. Fertilization was by a top-dressing of 6 g 14N-6.3P-11.6K controlled-release fertilizer. Irrigation was by hand watering as necessary.

Cluster length (excluding its peduncle) was measured weekly for 40 flower clusters per treatment until first flower opening in the cluster, and the time to anthesis was plotted against cluster length using the general linear models procedure (SAS Institute, 1990). Fifteen individual flowers in the $24 \mathrm{C}$ chamber were measured to correlate their lengths with those of the clusters.

Inflorescence buds were visible $\approx 21$ days after the start of treatment in the 21 and 24C chambers, but 6 to 7 weeks were required at 18C. Developing flower clusters were tagged with paper tags when 3 to $6 \mathrm{~mm}$ long. This size was achieved $\approx 5$ weeks after the start of treatment at 21 and $24 \mathrm{C}$ (not significantly different by the Waller-Duncan $\mathrm{K}$ ratio $t$ test at $\mathrm{K}$ ratio $=100$ ) and at $\approx 12$ weeks for the clusters on

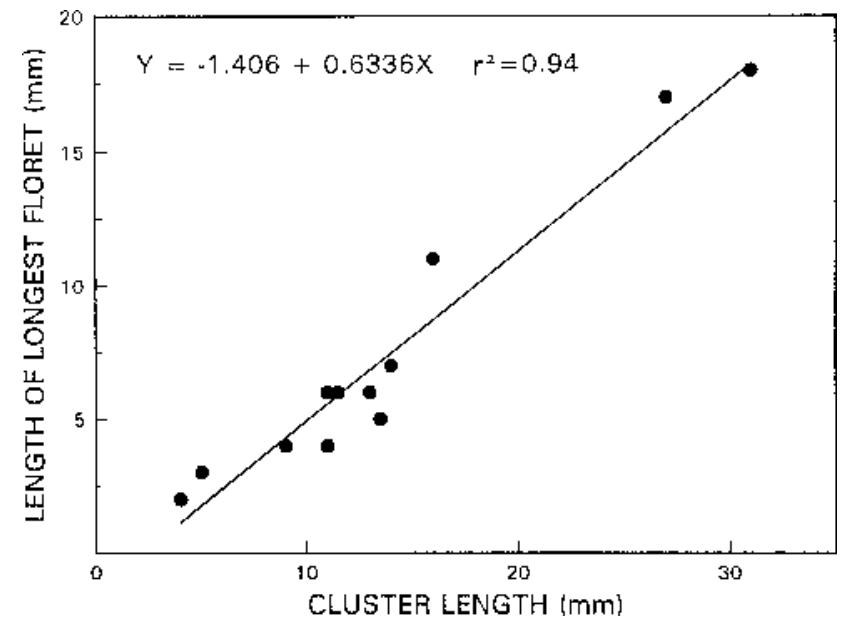

Fig. 1. Relationship of length of longest flower, including pedicel, vs. cluster length, excluding peduncle.

PAKALANA FLOWER CLUSTER DEVELOPMENT

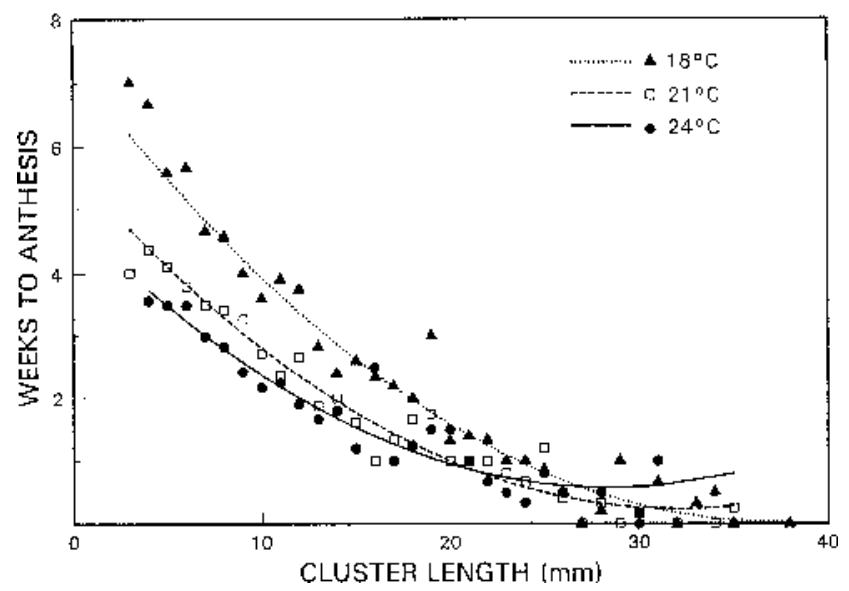

Fig. 2. Time, in weeks, to reach anthesis for pakalana flower clusters of varying lengths when grown at a 
plants at $18 \mathrm{C}$, which was significantly different than at the two higher temperatures. The intervals from the 6-mm stage to anthesis of the first flower were 3.5, 4.2, and 5.7 weeks for 24,21 , and $18 \mathrm{C}$, respectively. Total time to flower from the start of LD was significantly different for flower clusters at all three temperatures using the Waller-Duncan $\mathrm{K}$ ratio $t$ test at $\mathrm{K}$ ratio $=100$. These intervals were 9.0, 10.0 , and 17.4 weeks at 24,21 , and $18 \mathrm{C}$, respectively.

An individual flower opened when it was $\approx 15$ to $18 \mathrm{~mm}$ long and when the cluster was 25 to $33 \mathrm{~mm}$ long (Fig. 1). The flower pedicel comprised about one-half of the cluster length through most of the development period. Flower length did not differ in the three temperature conditions.

From a 6-mm cluster size, the development time to anthesis was longer at $18 \mathrm{C}$ than at 21 or $24 \mathrm{C}$ (Fig. 2). It was critical, however, that a cluster reach $6 \mathrm{~mm}$, as I observed that most cluster abortion occurred at shorter lengths. By the time a cluster was $20 \mathrm{~mm}$ long, however, the time to anthesis differed by only $\approx 3$ days: ranging from 7 days for clusters at 21 and $24 \mathrm{C}$ to 10 days for clusters at $18 \mathrm{C}$ (Fig. 2). The relationship illustrated in Figs. 1 and 2 permits prediction of flower opening by measurement of cluster length rather than the more difficult measurement of individual flowers in the cluster.

As with its near relative, stephanotis [Stephanotis floribunda (R. Br.) Brongn.] (Kofranek and Criley, 1983), pakalana flowering is induced by long photoperiods, but temperature influences the rate at which the inflorescence develops.

The night temperature in Hawaii can drop below 18C (to 15-16C) for periods of 2 to 3 weeks from late November through mid-February and would delay flower development.
This work demonstrates that a high-value lei flower can be economically produced during its off-season by providing long-day conditions. Even with lighting, growers should select locations where night temperatures are $21 \mathrm{C}$ or higher for rapid production of pakalana flowers for the winter lei trade. Lighting would need to begin $\approx 9$ to 10 weeks before the flowers are to be harvested.

\section{Literature Cited}

Arai, T., S. Hashimoto, and K. Furukawa. 1993. Volatile components of Telosma cordata Merrill flowers. Flavour Fragrance J. 8(4):221-223.

Criley, R.A. 1989. Some advances in lei flower production. Hort. Dig. (Hawaii) 89:6-8.

Kofranek, A.M. and R.A. Criley. 1983. Photoperiod and temperature effects on Stephanotis flowering. Acta Hort. 147:125-131.

SAS Institute. 1990. SAS/STAT user's guide, version 6. 4th ed. SAS Institute, Cary, N.C. 